\title{
CERTAIN OBSERVATIONS ON THE ACTION OF
} BILE AND BILE SALTS WITH AND WITHOUT THE ADDITION OF THE SALTS OF CALCIUM ON ANIMAL RED BLOOD CORPUSCLES.

\author{
By LEONARD S. DUDGEON, F.R.C.P. (LOND.). \\ (From the Department of Pathology, St Thomas's Hospital, London.)

\section{Human Bile.}

BILE is often referred to as if its chemical composition was constant and that by treating samples of bile with extractives similar results would be obtained, whereas samples of human bile differ to such an extent that the term bile in itself signifies little. Two samples of human bile may differ to such an extent that while one sample has the qualities of true bile as regards its bile salt content the other may be entirely devoid of lytic action on red blood cells. Numerous experiments made with human bile obtained during life and from the post mortem room have shown this to be correct. The actual bile salt content. of bile can be judged by boiling the bile to remove much of the protein, and also to destroy bacterial activity and then contrast the haemolytic activity of the treated sample with a 1 per cent. solution of bile salt in normal saline.

Some samples of human bile are extremely active as can be readily appreciated by a study of Table I. In addition to the action of human bile referred to in this table there is also a record of the action of 2 per cent. bile salt in saline so as to act as a control on the samples of bile which were found to be most active. It is shown here, that 2 per cent. bile salt in saline is not as active as two of the four samples of bile which are referred to.

The action of drainage of the gall bladder may be to remove the bile salt content of the bile, or more correctly what is termed bile for the first few days or may be even a week after the operation. The effect in some instances is most striking, as samples of bile which showed at 


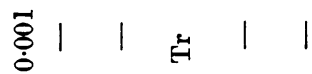

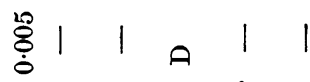

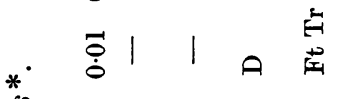

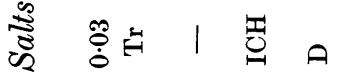

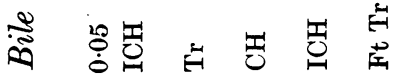

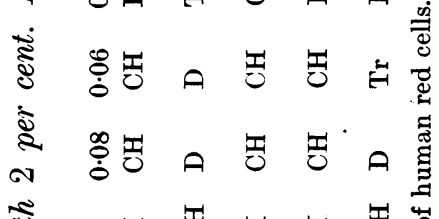

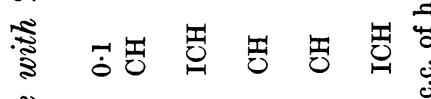

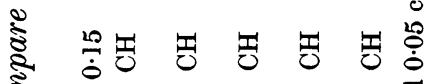

言

$\rightarrow$

思

要

हूँ

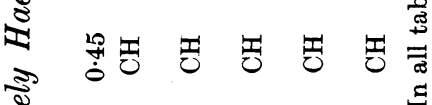

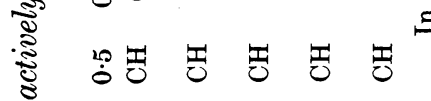

$s$

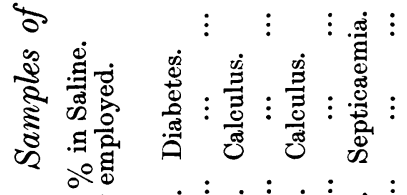

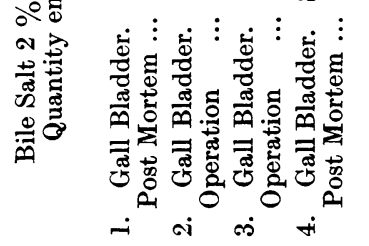

$\begin{array}{lllllllll}0 & 0 & 1 & 1 & 1 & 1 & 1 & 1\end{array}$

\begin{tabular}{llllllll}
\hline & $\vdots$ & 1 & 1 & 1 & 1 & 1 & 1
\end{tabular}

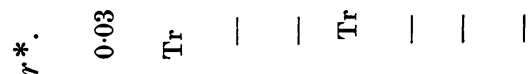

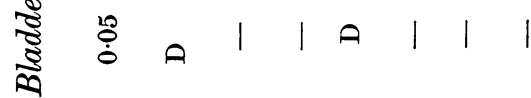

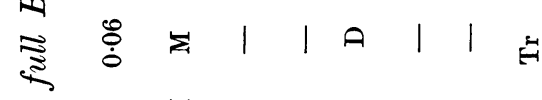

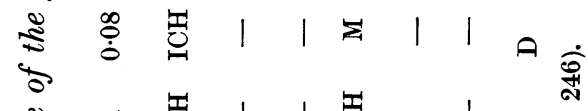

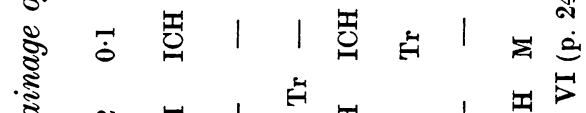

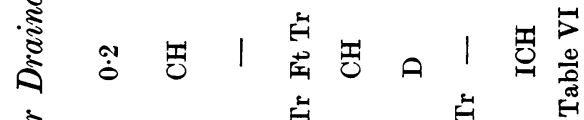

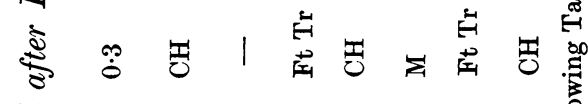

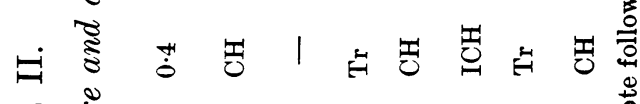

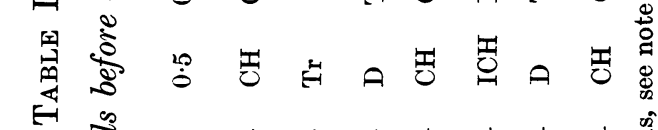

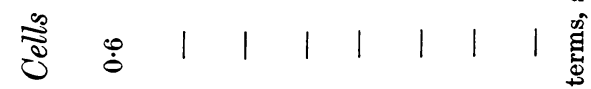

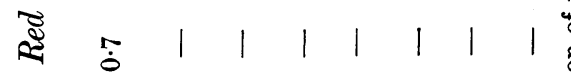

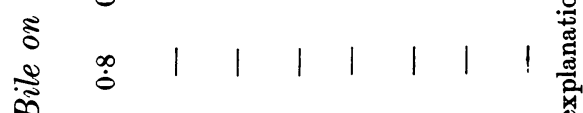

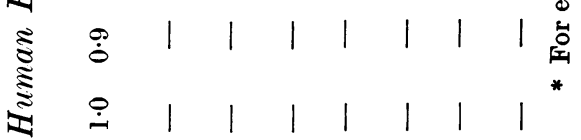

อ. : : ब

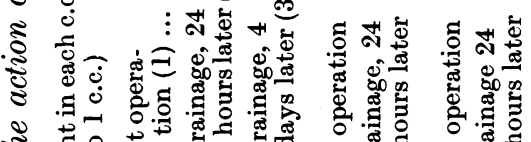

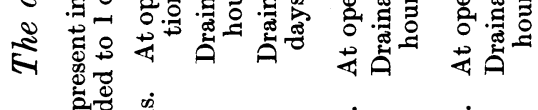

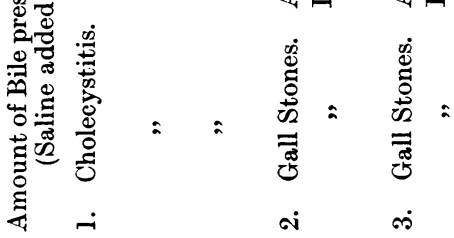


the actual operation a haemolytic value equal to or even greater than 1 per cent. bile salt, after operation may be reduced to a minimum, or the lytic action may be lost. Occasionally drainage may induce a flow of much more active bile than was found at the time of operation. These facts are well shown in Table II. Numerous experiments could be quoted to illustrate the wide differences which exist between the haemolytic action of various samples of human bile, but no useful purpose would be gained.

\section{The action of Human Bile and Bile Salts on different samples of Human Red Blood Corpuscles.}

The action of bile salts and human bile was tested on different samples of human red cells, e.g. normal cells, red cells from cases of obstructive jaundice and red cells from cases of congenital cholaemia, as by this means it was possible to compare the action on cells which are known to be most fragile and those which are most resistant in various strengths of sodium chloride in distilled water. No accurate distinction, however, could be obtained by the various methods employed as all human red cells appear to act in the same way with bile salt alone, or with bile salt in the presence of calcium.

\section{The effect of boiling Human Bile.}

Although boiling has no effect on the haemolytic activity of bile salts, yet, it may increase the activity of bile by removing the protein which may be present and thus permitting the bile salts to act fully. There was only one instance of a sample of bile in which the lytic action was reduced by boiling.

\section{The stimulating effect of Calcium on the lytic aCtion of Bile Salts.}

While blood serum inhibits the haemolytic action of human and animal bile, calcium exerts a directly opposite effect (Table III). It not only excites a stimulating action in that it increases the lytic effect on red cells, but moreover it greatly increases the rate of haemolysis.

The pure crystalline preparation of calcium chloride (Kahlbaum) was used in all experiments referred to in this communication. The effect of known quantities of calcium acting on red cells in the presence of a standard solution of bile salt is fully illustrated in Table IV; also the increased rapidity of haemolysis and the accentuated action of 
总 | | | | | |

造 $|1| a \mid$

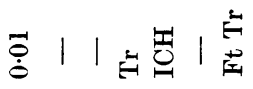

\%

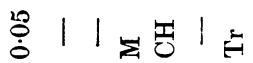

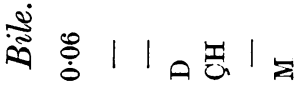

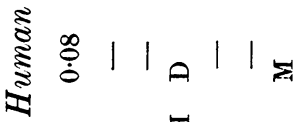

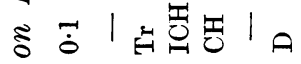

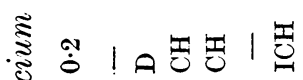

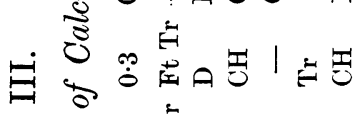

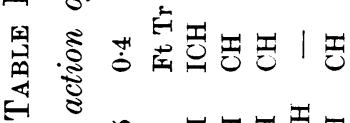

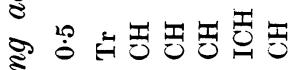
: 1 男 $|1|$ เุ

号

₹

ฐ

के

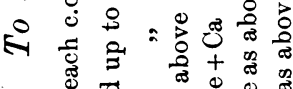
焉 =

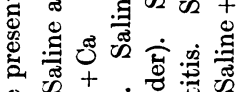

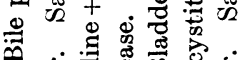

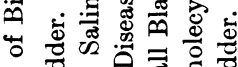
节

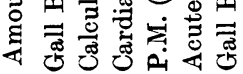

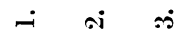

Journ. of Hyg. xvI

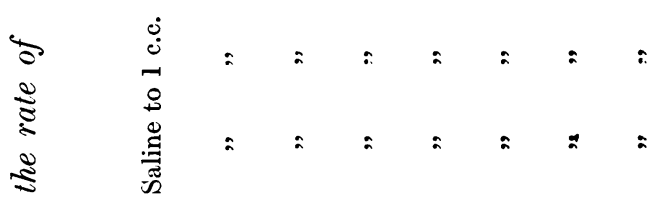

ธ

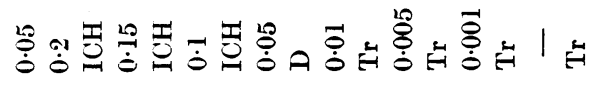

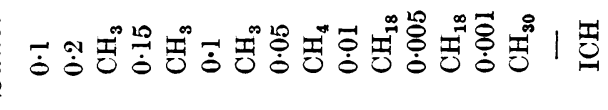

के

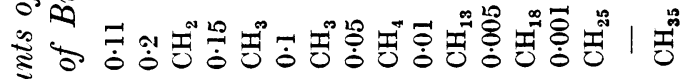

व

. 공 竎.

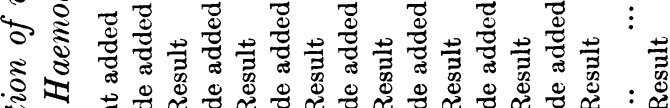

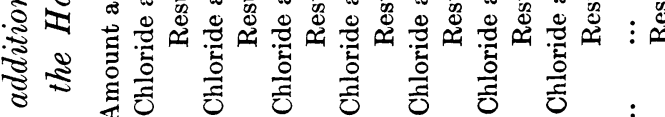
芯

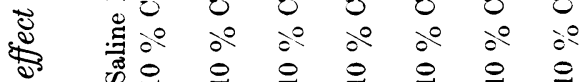

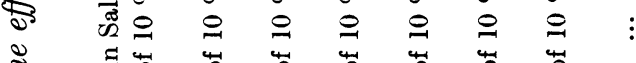

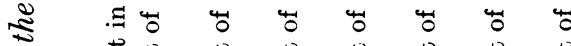

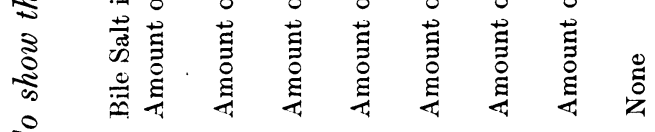


bile salt is fully emphasized. It is shown also in this communication how calcium increases the lytic action of bile salt on various samples of red cells and helps to distinguish between animal red cells, e.g. sheep and human. Various proportions of calcium chloride were added to the fluids which were being tested, but 0.05 c.c. of a 10 per cent. solution was generally found to be satisfactory, when the total bulk was made up to 1 c.c. It was found further that other preparations of calciumoxide and lactate-were capable of increasing the lytic action of bile salts.

A sample of pure barium chloride (Kahlbaum) was tested in a similar manner and found to increase the haemolytic activity of bile salts or bile. Sodium chloride employed for control purposes did not accentuate the activity of bile salts except in highly "salted" solutions (10 per cent. or over). The action of calcium in the presence of bile salts is controlled by blood serum, but this is referred to elsewhere in this communication.

To compare the action of Human, Sheep, Ox, and Guinea-pig Bile on the Red Cells of these animals with and without the addition of CaLCIUM.

In these experiments the bile was boiled for five minutes to exclude the action of living bacteria, except in the case of guinea-pig bile which was found to be sterile. In each tube a definite volume of bile was added and the whole made up to 1 c.c. with normal saline in one series of experiments, while in the other series the saline which was added contained 0.05 c.c. of a 10 per cent. solution of calcium chloride. The red cells obtained from the various animals were washed free from plasma and then 0.05 c.c. of the requisite cells was added to the mixture which was incubated at $37^{\circ} \mathrm{C}$. and the results recorded at the end of every few minutes until the hour had elapsed. A standard for bile does not exist so that every sample of bile must be treated on its own merits. The bile of various animals was tested on red cells, but only human, sheep, ox, and guinea-pig bile was tested systematically. Ox bile by this means was found to be the most active bile obtainable as most samples were more efficient than a 2 per cent. solution of bile salt. Human bile varied more than animal bile in its lytic values. It was possible, however, with all samples of bile employed for this purpose to differentiate between human, sheep, pig, and ox red cells. Ox bile or bile salt in solution in saline very readily haemolyses human red cells while the action on sheep red cells is much less effective, in fact, all samples of bile and bile salts act most readily on human cells and much less effec- 
tively on sheep cells. It is only necessary to compare the various samples of bile with a standard solution of 2 per cent. salt to determine the activity of the sample in question. Further this specific difference between human and sheep cells can be emphasized much more forcibly by the addition of calcium chloride to bile. It is possible that the difference between the red cells of various animals may depend on the lecithin content of the red cells as discussed in a separate paragraph in this communication.

The results of these experiments showing the action of human and ox bile on the red cells of various animals are recorded in Table V. Here also is clearly illustrated the striking difference in the action of bile salts, with and without calcium, on human and sheep red cells.

\section{The inhibitory action of Blood Serum on the haemolytic action of Bile and Bile Salts.}

It has already been stated that the effect of boiling human bile is to induce a greater activity in the boiled bile or to incite no obvious change. It is well known that the addition of blood serum to bile or bile salts diminishes the haemolytic action and further such haemolysis by bile salts can be removed by the addition of sufficient blood serum. Blood serum (human or:animal) can be employed for this purpose and it is a matter of no importance whether the serum is fresh or has been inactivated at $60^{\circ} \mathrm{C}$., as in each instance it serves to protect the red cells from the lytic activity of the salts. We know from experience that if too much blood is employed or too weak a solution of bile salt that the chances of obtaining a culture of the Bacillus typhosus from the blood stream is distinctly diminished. I know of several instances in the Eastern Mediterranean in 1915 where considerable improvement occurred in blood culture technique in cases of "Enterica" by doubling the strength of the bile salts and avoiding too much blood, as by this means the "protective action" of the serum is removed and its antibacterial properties rendered void. Experiments show that the lytic action of a standard solution of bile salt on red cells can be regulated exactly by means of blood serum, while the haemolytic action of bile salt may be unopposed in the presence of the body fluids. If we take the view that blood serum serves to protect the red cells from the injurious action of the bile, then by the addition of sufficient bile salt the whole of the "protective action" of the serum will be removed and thus the growth of such bacteria as are susceptible to the action of blood serum will be free to multiply. The body fluids as shown in 


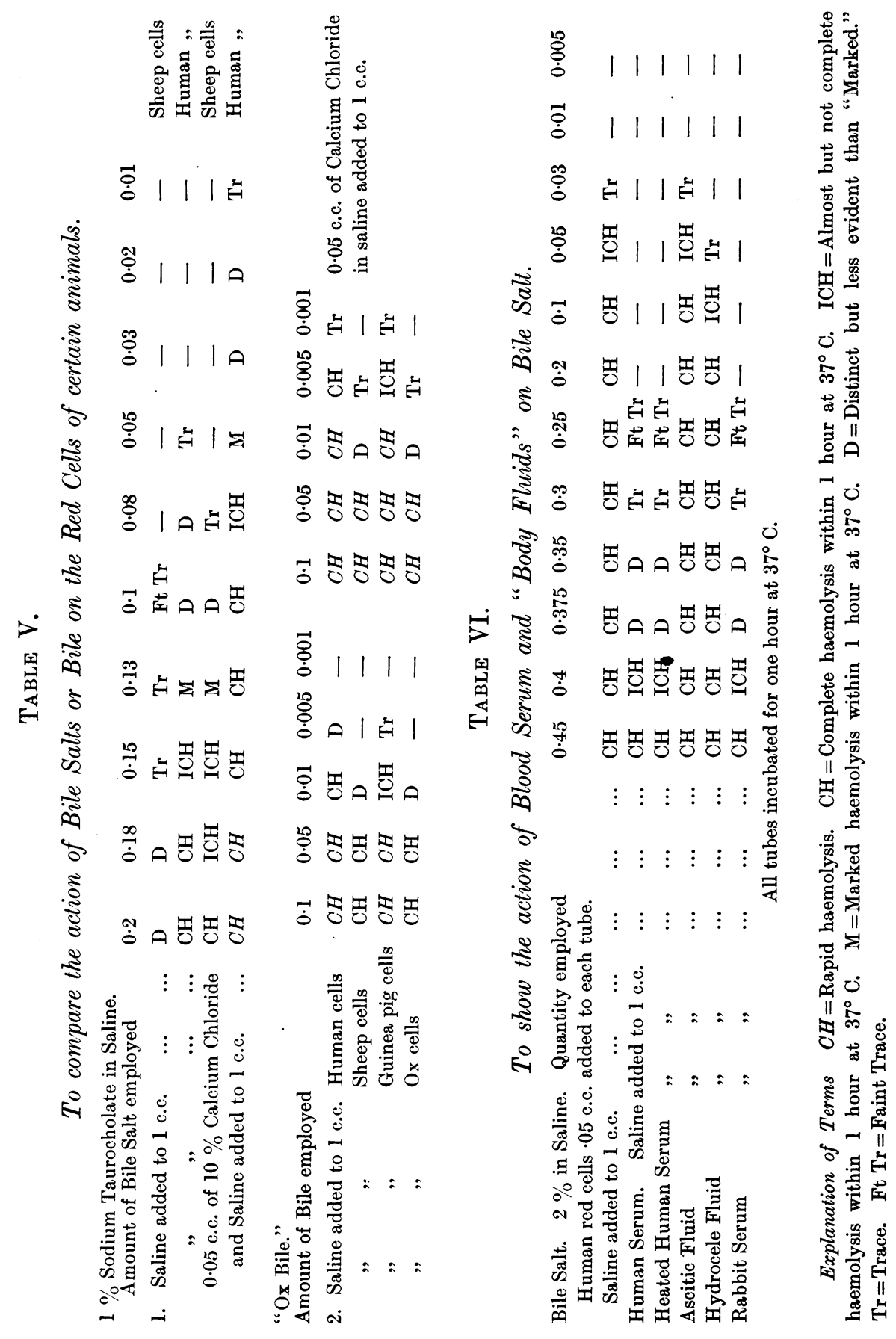


Table VI are very deficient in such protective action while numerous other experiments which were completed, but are not recorded, confirm this observation on the body fluids. In most instances it is unnecessary to employ such a strong solution of bile salt in the presence of the body fluids because the protective power of these fluids is feeble.

It was found possible, with the numerous samples of human bile which were tested and found to lyse red cells actively, to control this action exactly by the addition of the necessary quantity of blood serum. For example, bile removed at operation from a case of distended gall bladder haemolysed red cells completely in one hour when a 1 per cent. solution in saline was employed, but a 40 per cent. mixture of the bile in human serum failed to completely haemolyse the same sample of red cells during the same period ${ }^{1}$. In Table VI, to which reference has been made, it will be seen that a sample of ascitic fluid corresponds with "saline" while a sample of hydrocele fluid is only a little more effective in preserving the red cells from the action of bile salt. These comparative results of blood serum on the one hand and ascitic fluid on the other in relation to bile salt haemolysis are very similar to those which I obtained when studying the nature of the so-called aggressive fluids and the action exerted by the anti-aggressive agents of which blood serum is the most potent.

\section{The effect of treating Human Bile with Ether.}

Bile was obtained in bulk, centrifugalised, boiled for five minutes and then centrifugalised again. The more or less clear sample of bile was then cooled and ether was added in the proportion of about 200 c.c. to 20 c.c. of bile. The ether bile was then shaken for many hours in a large glass jar at room temperature, after which the ether was separated off, while that which was more intimately mixed with the bile was removed by means of the electric fan and a warm current of air until the original bulk of bile was obtained. It was found as a result of numerous experiments that the ether treated bile is a much more powerful agent in dissolving red cells than the untreated bile. In one sample of bile it was found that a 1 in 10 dilution produced a trace of haemolysis, while the same bile after treatment with ether produced a similar effect when diluted 1 in 100. Another sample produced a trace of haemolysis with a dilution of 1 in 3 , while after treatment it induced a trace of haemolysis when diluted 1 in 10 . The action of ether-treated bile may depend

1 It has been conclusively demonstrated that blood serum effectively controls bile salt haemolysis even when calcium is acting with the bile salt. 
upon substances extracted from the bile which hinder the haemolytic properties of bile salts in the untreated samples, or this altered action might be explained by the assumption that ether had set free a substance which acted as a haemolytic agent in addition to the bile salts. The commercial preparation of bile salts already referred to was similarly treated with ether, but no such effect was induced as judged by the haemolytic activity of these salts in the control experiments.

\section{Lecithin content of Red Cells.}

The results recorded in this communication show that bile salt, or samples of bile, lyse the red cells of various animals with a widely different haemolytic activity. The human red cell is absolutely distinct from the sheep cell in this respect as the former is relatively fragile in the presence of these solvents. The efficiency of bile salts is greatly accentuated in the presence of calcium and it appeared probable that the explanation for this phenomenon might be an inter-action between calcium and the lecithin in the red cell. It is well known that calcium is able to precipitate lecithins, and, therefore, it was thought possible that the lecithin content of the red cells of various animals might vary. This was shown to be the case as regards human and sheep cells in the experiments arranged.

Fresh sheep and human blood was obtained in bulk into citrated saline, centrifugalised, and thoroughly washed in saline. The red cells were then collected, dried rapidly by means of an electric fan, and finally were handed to Dr Hugh Maclean, Pathological Chemist to St Thomas's Hospital, who dried them to a constant weight in a vacuum chamber, and the lecithin content was then estimated by methods which in his experience on this subject are considered to be most suitable.

The analysis completed by Dr Maclean is as follows:

Human Red Cells $2 \cdot 21 \mathrm{mgms}$. per cent. of phosphorus

Sheep Red Cells 1.35 ,, , , , ,

Note:-This work has had to be abandoned for the present, but will be continued later with the hope that it may be possible to obtain definite facts of importance from the determination of the lecithin content of animal red cells and from the red cells in diseases affecting the human body.

\section{REFERENCE.}

Dudgeon, Leonard S. Croonian Lectures. Roy. College of Physicians, Lond. The Nature of so-called aggressive exudates. 